\title{
Autologous Bone Marrow Mesenchymal Stem Cell Transplantation in Liver of a Patient with Liver Cirrhosis: Case Report
}

\author{
Boyukkishi A. Agaev, MD, $\mathrm{PhD}, \mathrm{ScD}^{1}$; Rauf M. Agaev, MD, PhD, $\mathrm{ScD}^{2}$; \\ Andrey G. Popandopulo, MD, PhD, $\mathrm{ScD}^{3}$; Rasim E. Jafarli, MD, $\mathrm{PhD}^{2 *}$ \\ ${ }^{I}$ Scientific Center of Surgery named after M.Topchubashov, Baku, Azerbaijan \\ ${ }^{2}$ Azerbaijan Medical University, Baku, Azerbaijan \\ ${ }^{3} V . K$. Gusak State Institute of Emergency and Reconstructive Surgery of the NAMS, \\ the International Center of Biotechnology "Biostem", Donetsk, Ukraine
}

\begin{abstract}
This report presents a clinical case describing successful endovascular transplantation of autologous bone marrow mesenchymal stem cells (MSCs) into liver of a patient with liver cirrhosis.
\end{abstract}

Keywords: mesenchymal stem cells; transplantation; liver cirrhosis.

\section{Introduction}

Liver cirrhosis (LC) remains a major challenge of modern medicine. According to the Global Burden of Disease 2010 study, liver cirrhosis caused 31 million Disability Adjusted Life Years (DALYs), or 1.2\% of global DALYs, in 2010, and one million deaths, or $2 \%$ of all deaths worldwide in that year $[1,2]$. Currently, the arsenal of tools aimed at improving the functional state of the liver and other organs and systems affected by LC has been significantly increased, but the results of treatment remain unsatisfactory. A relatively radical method for treatment of LC patients is liver transplantation. However, in the near future it will not be possible to provide patients with donors in the demanded volumes, as well as organize this service in many hospitals, for a number of scientific and economic reasons [3]. The above data have caused a search for more affordable and effective methods for treatment of LC patients. In this respect, the data on the successful results of transplantation of different kinds of stem cells used to stimulate reparative processes in damaged tissues of various organs have a great scientific and practical interest [4-8]. Below we present a clinical case describing successful endovascular transplantation of autologous bone marrow mesenchymal stem cells (MSCs) into liver of a patient with liver cirrhosis.

\footnotetext{
*Corresponding author: Rasim E. Jafarli, MD, PhD. Azerbaijan Medical University, Baku, Azerbaijan E-mail: $\underline{d r}$ jafarli@mail.ru
}

\section{Case presentation}

The 56-year-old man who is the subject of this report was admitted to the surgical department of the Institute of Emergency and Reconstructive Surgery, named after V.K. Gusak of NAMS of Ukraine, with acute gastrointestinal bleeding. The patient reported general weakness, malaise, fatigue, bloating, and bloody vomiting. He had the experience of drinking alcohol, although he did not suffer from chronic alcoholism. He denied any history of viral hepatitis.

A physical examination revealed a severe clinical condition; the skin and sclera were pale, slightly icteric. The abdominal palpation revealed a slight pain in the right upper quadrant and epigastric zone. The liver was enlarged and splenomegaly was marked. Hemodynamic instability was noted (BP - 90/50 mmHg, pulse - $100 \mathrm{bpm}$ ). The heart sounds were muffled. Auscultation of the lungs revealed vesicular breathing, which was weakened in the lower lung fields.

Blood test: HB - $76 \mathrm{~g} / \mathrm{L}, \mathrm{Er}-3.7^{\times} 10^{12} / \mathrm{L}$, platelets $180,000 / \mathrm{mL}$, and leukocytes $-5,6^{\times} 10^{9} / \mathrm{L}$; ESR $-56 \mathrm{~mm} / \mathrm{h}$; total protein $-76 \mathrm{~g} / \mathrm{L}$; albumin - $28 \mathrm{~g} / \mathrm{l}$; total bilirubin - 36 $\mathrm{mmol} / \mathrm{l}$; ALT $-136 \mathrm{IU} / \mathrm{L}$ and AST $-185 \mathrm{IU} / \mathrm{L}$; blood glucose was $3.5 \mathrm{mmol} / \mathrm{L}$.

Hepatitis viruses were not found in the patient. Abdominal sonography revealed hepatomegaly, splenomegaly, and a moderate amount of free fluid; the structure of the liver was non-uniform and the diffuse changes of parenchyma were noted. Portal vein diameter was $1.2 \mathrm{~cm}$; the portal blood flow 
was $420 \mathrm{ml} / \mathrm{min}$. During EGD, we identified varicose veins of the esophagus and stomach of III degree, which were the cause of the bleeding. Bleeding was stopped by clipping these veins. A liver biopsy of the avascular zone was performed under local anesthesia and ultrasound control. Monoject ABC needles (Sherwood Medical) were used. The severity of cirrhosis was evaluated by Child-Pugh criteria. The ChildPugh class B was defined.

The patient underwent intensive treatment and preventive measures aimed at preventing re-bleeding, improving the functional capacity of the liver and kidneys. A week later, the patient was discharged to home in good condition with the recommendation to observe a strict diet that excluded alcohol. A month later, after re-examination, we harvested bone marrow for transplantation of autologous MSCs into the liver. The patient was aware of the planned method of transplantation, possible side effects, and complications. Written informed consent was obtained.

The culture of autologous MSCs was isolated from the bone marrow obtained by puncture of the iliac crest (2 months before MSCs transplantation). Bone marrow aspirate was diluted by Hank's balanced salt solution (HBSS) in a ratio of $1: 2.5$. Density gradient separation medium Histopaque ${ }^{\circledR}-1077$ was added to a $50-\mathrm{ml}$ centrifuge tube ( $1 \mathrm{ml}$ per $1 \mathrm{ml}$ of the bone marrow). The bone marrow cell suspension was carefully layered on top of the gradient. After that, the tube was centrifuged at room temperature at 1800 $2000 \mathrm{rpm}$ for $30-40$ minutes. The interphase cells containing MSCs were collected in a 15-ml centrifuge tube with a small amount of HBSS and re-suspended. The tube was centrifuged at $800-1000$ rpm for $8-10$ minutes. Supernatant was removed; the precipitate was re-suspended in HSSS and centrifugation was repeated twice. After that, the precipitate was mixed with growth medium containing DMEM/F12 (Sigma, USA), 20\% FBS ("Biolot", Russia), and mitogens, and then suspension was seeded onto $75 \mathrm{~cm}^{2}$ plastic flasks at a density of $1-2 \times 10^{5}$ cells $/ \mathrm{cm}^{2}$ and placed in a carbon dioxide incubator for 3 days $\left(37^{\circ} \mathrm{C}, 5 \% \mathrm{CO} 2\right)$. Next, the medium was replaced and nonadherent cells were removed. The medium replacement took place every 2 days. The term of autologous MSCs cultivation was 42 days.

For identification and characterization of MSCs, the basic criteria recommended by the International Society of Cell Technologies in 2006 were applied:

(a) MSCs must be adherent to plastic under standard tissue culture conditions;

(b) MSCs must express certain cell surface markers such as CD73, CD90, and CD105, and lack expression of other markers including CD45, CD34, CD14, or CD11b, CD79alpha or CD19 and HLA-DR surface molecules;

(c) MSCs must have the capacity to differentiate into osteoblasts, adipocytes, and chondroblasts under in vitro conditions.

On day 42 after MSC cultivation, the patient was readmitted to the hospital for SMSCs transplantation into the liver. Manipulation was carried out in a specially equipped operating room to perform endovascular interventions. After pre-sedation, under local anesthesia and X-ray control, we catheterized $a$. hepatica propria through the femoral approach; then the cultured autologous MSCs were intro-arterial injected. The manipulation underwent well. Complications directly related to the manipulation were not. As seen in Figure 1, the arterial tree of liver surface was impaired. After the procedure, the patient was transferred to the surgical department and discharged home 3 days later in satisfactory condition.

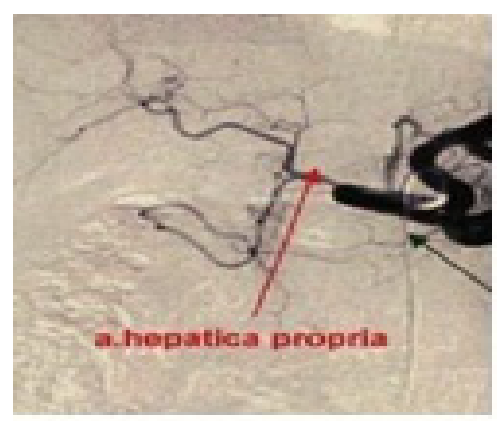

Figure 1. SMSC transplantation into a. hepatica propria

During the follow-up 2 months after transplantation, clinical improvement was revealed, as well as positive dynamics in the laboratorial parameters. We also noted a decrease in the severity of astheno-vegetative syndrome, disappearance of ascites, anemic and thrombocytopenic syndromes, improvement of protein-synthetic liver function (increased albumin levels), and a reduction phenomena cytolysis (decrease in the levels of thymol test and ALT). A follow-up examination at the end of the year after intra-arterial MSCs transplantation into liver revealed positive trends both in the subjective symptoms and laboratory-instrumental investigations. Objectively: a icterus ("jaundice") was not observed, the general condition of the patient was improved, and malaise has not occurred within the specified period of observation. Ascites was also not detected by ultrasound. Portal blood flow was $460 \mathrm{ml} / \mathrm{min}$. Laboratory parameters also showed a positive trend: $\mathrm{Hb} 108 \mathrm{~g} / \mathrm{L} ; \mathrm{Er}-3.5^{\times} 10^{12} / 1$; platelets

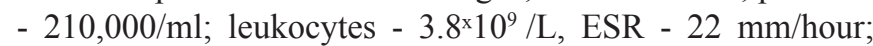
total bilirubin - $22 \mu \mathrm{mol} / \mathrm{L}$, total protein $98 \mathrm{~g} / \mathrm{L}$; albumin - 40 g/1; ALT - $86 \mathrm{IU} / \mathrm{L}$; ACT - $92 \mathrm{IU} / \mathrm{L}$; thymol test - 1.9; blood glucose was $4.2 \mathrm{mmol} / \mathrm{L}$.

Thus, the above data showed high clinical efficacy of the intra-arterial administration of MSCs via the hepatic artery in a patient with liver cirrhosis.

\section{Competing interests}

The authors declare that they have no competing interests.

\section{References}

1. Murray CJ, Vos T, Lozano R, Naghavi M, Flaxman AD, Michaud C, et al. Disability-adjusted life years (DALYs) for 291 diseases and injuries in 21 regions, 1990-2010: a systematic analysis for the Global Burden of Disease Study 2010. Lancet 2012; 380(9859):2197-223. 
2. Lozano R, Naghavi M, Foreman K, Lim S, Shibuya $\mathrm{K}$, Aboyans $\mathrm{V}$, et al. Global and regional mortality from 235 causes of death for 20 age groups in 1990 and 2010: a systematic analysis for the Global Burden of Disease Study 2010. Lancet 2012; 380(9859):2095-128.

3. Masson S, Harrison DJ, Plevris JN, Newsome PN. Potential of hematopoietic stem cell therapy in hepatology: a critical review. Stem cells 2004; 22(6): 897-907.

4. Am Esch JS 2nd, Knoefel WT, Klein M, Ghodsizad A, Fuerst G, Poll LW, et al. Portal application of autologous CD133+ bone marrow cells to the liver: a novel concept to support hepatic regeneration. Stem Cells 2005; 23(4): 463-70. 5. Fujii H1, Hirose T, Oe S, Yasuchika K, Azuma H, Fujikawa T, et al. Contribution of bone marrow cells to liver regeneration after partial hepatectomy in mice. J Hepatol 2002; 36(5): 653-9.

6. Kakinuma S1, Tanaka Y, Chinzei R, Watanabe M, Shimizu-Saito K, Hara Y, et al. Human umbilical cord blood as a source of transplantable hepatic progenitor cells. Stem Cells 2003; 21(2):217-27.

7. Kharaziha P, Hellström PM, Noorinayer B, Farzaneh F, Aghajani K, Jafari F, et al. Improvement of liver function in liver cirrhosis patients after autologous mesenchymal stem cell injection: a phase I-II clinical trial. Eur J Gastroenterol Hepatol 2009; 21(10):1199-205.

8. Wei X1, Yang X, Han ZP, Qu FF, Shao L, Shi YF. Mesenchymal stem cells: a new trend for cell therapy. Acta Pharmacol Sin 2013; 34(6):747-54. 